\title{
The UAE healthy future study: a pilot for a prospective cohort study of 20,000 United Arab Emirates nationals
}

\author{
Abdishakur Abdulle', Abdullah Alnaeemi ${ }^{2}$, Abdullah Aljunaibi², Abdulrahman Al Ali², Khaled Al Saedi², \\ Eiman Al Zaabi ${ }^{3}$, Naima Oumeziane ${ }^{3}$, Marina Al Bastaki ${ }^{3}$, Mohammed Al-Houqani ${ }^{4}$, Fatma Al Maskari ${ }^{4}$, \\ Ayesha Al Dhaheri ${ }^{4}$, Syed M. Shah ${ }^{4}$, Tom Loney ${ }^{4}$, Mohamed El-Sadig ${ }^{4}$, Abderrahim Oulhaj ${ }^{4}$, Leila Abdel Wareth ${ }^{5}$, \\ Wael Al Mahmeed ${ }^{5}$, Habiba Alsafar ${ }^{6}$, Benjamin Hirsch ${ }^{6}$, Fatme Al Anouti ${ }^{7}$, Jamila Yaaqoub ${ }^{8}$, Claire K. Inman ${ }^{1}$, \\ Aisha Al Hamiz', Ayesha Al Hosani ${ }^{1}$, Muna Haji ${ }^{1}$, Teeb Alsharid ${ }^{1}$, Thekra Al Zaabi ${ }^{1}$, Fatima Al Maisary', \\ Divya Galani ${ }^{1}$, Tim Sprosen ${ }^{9}$, Omar El Shahawy ${ }^{10}$, Jiyoung Ahn ${ }^{10}$, Tomas Kirchhoff ${ }^{10}$, Ravichandran Ramasamy ${ }^{10}$, \\ Ann Marie Schmidt ${ }^{10}$, Richard Hayes ${ }^{10}$, Scott Sherman ${ }^{10}$ and Raghib Ali $^{1 *}$ (D)
}

\begin{abstract}
Background: The United Arab Emirates (UAE) is faced with a rapidly increasing burden of non-communicable diseases including obesity, diabetes, and cardiovascular disease. The UAE Healthy Future study is a prospective cohort designed to identify associations between risk factors and these diseases amongst Emiratis. The study will enroll 20,000 UAE nationals aged $\geq 18$ years. Environmental and genetic risk factors will be characterized and participants will be followed for future disease events. As this was the first time a prospective cohort study was being planned in the UAE, a pilot study was conducted in 2015 with the primary aim of establishing the feasibility of conducting the study. Other objectives were to evaluate the implementation of the main study protocols, and to build adequate capacity to conduct advanced clinical laboratory analyses.
\end{abstract}

Methods: Seven hundred sixty nine UAE nationals aged $\geq 18$ years were invited to participate voluntarily in the pilot study. Participants signed an informed consent, completed a detailed questionnaire, provided random blood, urine, and mouthwash samples and were assessed for a series of clinical measures. All specimens were transported to the New York University Abu Dhabi laboratories where samples were processed and analyzed for routine chemistry and hematology. Plasma, serum, and a small whole blood sample for DNA extraction were aliquoted and stored at $-80^{\circ} \mathrm{C}$ for future analyses.

Results: Overall, 517 Emirati men and women agreed to participate (68\% response rate). Of the total participants, 495 (95.0\%), 430 (82.2\%), and 492 (94.4\%), completed the questionnaire, physical measurements, and provided biological samples, respectively.

Conclusions: The pilot study demonstrated the feasibility of recruitment and completion of the study protocols for the first large-scale cohort study designed to identify emerging risk factors for the major non-communicable diseases in the region.

Keywords: Adult, Chronic disease, Cohort studies, Pilot projects, Prospective studies, Public health, United Arab Emirates

\footnotetext{
* Correspondence: raghib.ali@nyu.edu

${ }^{1}$ New York University Abu Dhabi, Abu Dhabi, United Arab Emirates

Full list of author information is available at the end of the article
} 


\section{Background}

The United Arab Emirates (UAE), a high-income developing country, has undergone a rapid epidemiological transition from a traditional semi-nomadic society to a modern affluent society with a lifestyle characterized by over-consumption of energy-dense foods and low physical activity [1-3]. As a result, the UAE is facing an increasing burden of non-communicable diseases (NCD) including obesity, diabetes, and cardiovascular disease (CVD).

More than a quarter (29\%) of all deaths in the UAE are attributable to cardiovascular disease (CVD) [4], with a high prevalence of cardiometabolic risk factors [5]. Recent population-wide data showed that over $65 \%$ of adults are either overweight or obese, with $57 \%$ having central obesity [6]. Compared to the United States, one of the countries with the highest obesity burden, the rate of pre-diabetes or diabetes in the UAE, is far higher at $44 \%$ [1], according to the criteria from the American Diabetes Association (ADA).

This increasing burden of non-communicable diseases (NCDs) is largely attributable to complex co-determinants and risk factors including individual health habits (e.g., smoking, diet, and physical activity) [7], environmental factors [8], genetic susceptibility [9], human microbial milieu (microbiome) [10], and socioeconomic conditions [11].

For example, one-quarter of men were reported to regularly smoke; mostly cigarettes and to a lesser extent Midwakh and water pipe (hookah/shisha) [12]. The use of tobacco is also increasing rapidly among adolescents [13]. In addition, poor nutritional intake and physical inactivity are common, particularly among females [2]. The consumption of protective dietary factors (e.g. fruits, vegetables, nuts, whole grains) is suboptimal, whereas consumption of harmful foods (e.g. processed meat, red meet, and trans fatty acids) are above recommended levels [5]. Despite the lack of population-wide studies using objective measures of free-living physical activity, low levels of physical activity, mostly due to cultural and climate restrictions, have been self-reported in adolescent females [14].

To date, no large prospective cohort studies have been carried out in the UAE, hence, the relative importance of both established and novel risk factors for NCDs is largely unexamined (A small sample of Emiratis was recruited into the PURE study [15]). Therefore, the UAE Healthy Future study (AEHFS), a prospective longitudinal cohort, is designed to recruit 20,000 healthy UAE nationals. For the sample size calculation, we focus on risk factors for Diabetes. The 20,000 figure is the minimum number that will enable us to quantify associations between exposures such as physical activity, BMI, Vitamin $\mathrm{D}$ levels and incident diabetes. As this is a prospective cohort study whose primary objective is to understand the association between risk factors and outcomes, a fully representative sample is not required. Thus we are recruiting a convenience sample - this is the same approach taken by many similar cohort studies including, for example, the UK biobank \& Qatar biobank studies [17, 25].

Essentially, we conducted a pilot study to establish both the study feasibility and to ensure that all protocols and participant materials were appropriate for the local population.

The pilot study had five main objectives: 1) develop participant materials including the information leaflet, consent form, and questionnaires; 2) assess participation rates for various recruitment strategies; 3) evaluate the baseline assessment visit; 4) assess procedures for biological sample collection, transport and processing; and 5) assess participant acceptability of the individual study components. Here, we present our experience of conducting the pilot study and the results in relation to these five objectives.

\section{Subjects and methods \\ Subjects}

The AEHFS is designed to collect detailed self-reported data in a questionnaire, take physical measurements, and collect biological specimens - blood, urine, and mouthwash samples from 20,000 UAE nationals aged $\geq 18$ years. To test the feasibility of the study, we recruited 500 subjects. None of the participants received any incentives.

\section{Methods}

\section{Development of participant materials}

The first stage of the pilot study (September to December 2014) was a series of focus group discussions with potential participants to develop and optimize the participants' information material and study protocols, the results of which has been published elsewhere [16].

After completion of the focus group discussions, we revised materials and carried out the actual pilot study as described here.

\section{Assessment of participation rates for various recruitment strategies}

Making use of modifications suggested from the focus groups, the second stage of the pilot (actual recruitment of 500 participants into the cohort study) was carried out from January to April 2015 at two sites: Zayed Military Primary Health Care Clinic (ZMH PHCC) and the Abu Dhabi Blood Bank (ADBB), both of which are licensed for clinical research by the Health Authority of Abu Dhabi (HAAD). In each location, individuals who visited the clinic either for bi-annual medical screening (at the $\mathrm{ZMH} \mathrm{PHCC}$ ) or to donate blood (at ADBB) were 
invited to participate in the study. About $100 \mathrm{UAE}$ nationals visit the $\mathrm{ZMH} \mathrm{PHCC}$ daily whereas the ADBB receives about $20 \mathrm{UAE}$ nationals daily on average.

All potential participants were given participant information leaflets in either Arabic or English to read and had the opportunity to ask questions prior to completion of the recruitment process. The age and gender of nonrespondents, and their reasons for not participating was also recorded.

\section{Evaluation of baseline assessment visit}

All participants were asked to complete a selfadministered questionnaire on a touch screen tablet computer. Many of the questions were similar to the UK Biobank Study, a prospective cohort study of 500,000 adults in the UK [17]. The baseline questionnaire focused on known and potential risk factors for important public health outcomes including obesity, diabetes, and CVD [18]. These included questions on socio-demographic factors, lifestyle/habits, tobacco use, family history and early life exposures, general health, and psychological state (using PHQ-8, the Personal Health Questionnaire Depression Scale) $[19,20]$. In the pilot study, we used the International Physical Activity Questionnaires (IPAQ) to measure physical activity.

Questions were selected based on their relevance, reliability, simplicity, and likelihood to show plausible associations with NCDs. Culturally or religiously sensitive questions such as questions on alcohol consumption - which is prohibited for Muslims in the UAE - were excluded.

The questionnaire was translated from English into Arabic and back-translated into English to check for linguistic validity. For the Personal Health Questionnaire Depression Scale (PHQ-8) and the STOP-BANG Questionnaire for Obstructive Sleep Apnea we used previously validated Arabic translations [21]. The time taken to complete the questionnaire and the response distributions for each question were examined. In a face-toface interview, administered by a trained nurse, participants were asked about their medication history, past operations and other past medical history; and their fasting status. A summary of the questionnaire components is shown is Table 1. Dietary assessment will be conducted in the main study through the use of an online 24-h recall being developed for the use in the UAE. The full questionnaire is given in Additional file 1.

\section{Physical and clinical measurements}

We measured sitting and standing height using a stadiometer (Seca, HamburgDeutschland) and neck, hip, and waist circumferences using a standard tape according to international guidelines [22]. Body mass and bio- impedance were measured and body mass index (BMI) was automatically calculated as body weight $(\mathrm{kg}) /$ height square (meters) using the Tanita MC 780 (Tanita Inc., Tokyo, Japan).

Body weight was categorized based on BMI readings [underweight $\left(<18.5 \mathrm{~kg} / \mathrm{m}^{2}\right)$, normal range (18.5$\left.24.9 \mathrm{~kg} / \mathrm{m}^{2}\right)$, overweight $\left(25.0-29.9 \mathrm{~kg} / \mathrm{m}^{2}\right)$, obese class I $\left(30.0-34.9 \mathrm{~kg} / \mathrm{m}^{2}\right)$, obese class II $\left(35.0-39.9 \mathrm{~kg} / \mathrm{m}^{2}\right)$, obese class III $\left.\left(\geq 40.0 \mathrm{~kg} / \mathrm{m}^{2}\right)\right]$ according to world Health Organization categories. Pre-diabetes and diabetes were classified according to HbA1c levels: Normal: HBA1C < 5.7\%; Pre-diabetes (5.7-6.4\%); Diabetes HBA1c $>6.5 \%$. Hypertension was classified as normal: SBP (90$119 \mathrm{mmHg})$ and DBP (60-79 $\mathrm{mmHg})$, Prehypertension: SBP (120-139 mmHg) or DBP (80-89 $\mathrm{mmHg})$, Stage 1 hypertension: SBP $(140-159 \mathrm{mmHg})$ or DBP $(90-$ $99 \mathrm{mmHg}$ ), Stage 2 hypertension: $\mathrm{SBP} \geq 160$ or $\mathrm{DBP} \geq$ $100 \mathrm{mmHg}$ [23]. Hypercholesterolemia was defined by total cholesterol levels: desirable $<200 \mathrm{mg} / \mathrm{dl}$, borderline high 200-239 mg/dl, and high <240 mg/dl [24].

Hand-grip strength measurements were taken three times on participants' right and left hand using a hydraulic hand dynamometer (Jamar Plus Digital Hand Dynamometer J00105, Jamar, USA) [22], and the highest reading was recorded for each hand-grip. Brachial blood pressure readings were taken twice on the upper left arm with appropriate cuff size with a two-minute interval between readings using a semi-automated sphygmomanometer (Omron M10-IT, Omron corporation, Kyoto, Japan). If the difference in blood pressure readings was $\geq 5 \mathrm{mmHg}$, then a third reading was obtained. A summary of the physical measurements components is shown is Table 2.

\section{Assessment of procedures for biological sample collection, transport, and processing}

To ensure that all sample handling and analyses could be completed at NYUAD, laboratories for clinical chemistry, hematology, and immunology were established prior to the actual recruitment process.

At the assessment centre, a unique barcode was generated for each individual. Samples, along with participants' signed consent forms were labelled accordingly.

Participants provided several non-fasting specimens including blood ( $8 \mathrm{ml} \mathrm{SST}$ tube, and $8 \mathrm{ml}$ Plasma EDTA tube), mouthwash in $10 \mathrm{ml}$ of physiological normal saline $(0.9 \%)$, and the urine sample (approximately $10 \mathrm{ml}$ ) in a sterile screw-capped urine container. SST tubes were centrifuged ( $3500 \mathrm{rpm}, 4{ }^{\circ} \mathrm{C}$, for $15 \mathrm{~min}$ ), but not separated, within $30 \mathrm{~min}$ from the time of collection. All samples were refrigerated $\left(4{ }^{\circ} \mathrm{C}-8{ }^{\circ} \mathrm{C}\right)$ and subsequently transported to NYUAD laboratories in a temperaturecontrolled cooler with adequate spill control contingency plans. On arrival, SST samples were aliquoted in $1.5 \mathrm{ml}$ Eppendorf tubes. A proportion of the fresh serum was 
Table 1 Summary of baseline questionnaire components of the UAE healthy future pilot study

\begin{tabular}{ll}
\hline Measurement category & Instrument detail \\
\hline $\begin{array}{l}\text { Self-reported Questionnaires } \\
\text { Sociodemographic }\end{array}$ & $\begin{array}{l}\text { Employment status, Marital status, education, income, car ownership, } \\
\text { and household size including workers. }\end{array}$ \\
Family history and early life exposures & $\begin{array}{l}\text { Family history of major diseases, birth weight, breastfeeding, parental } \\
\text { smoking, childhood body size, residence at birth }\end{array}$ \\
Psychosocial factors & Anxiety, depression, social support \\
Environmental factors & Current address, current (or last) occupation, housing, means of travel, shift work \\
Lifestyle & Smoking, physical activity, diet, sleep \\
Health status & Medical history, medications, disability, reproductive history (women) \\
Nurse interview questionnaire & Current and previous clinical history of the participants and and use of prescription medications
\end{tabular}

analyzed for routine chemistry using Beckman DXC 600 (Beckman, USA). Regarding the EDTA tubes, a small whole blood sample was aliquoted and stored at $-80{ }^{\circ} \mathrm{C}$ for future DNA extraction prior to sample separation. Remaining EDTA sample, was centrifuged (3500 rpm, $4{ }^{\circ} \mathrm{C}$, for $15 \mathrm{~min}$ ). Plasma ETDA was aliquoted in $1.5 \mathrm{ml}$ Eppendorf tubes and stored at $-80{ }^{\circ} \mathrm{C}$. A complete list of the biochemical markers being analyzed is summarized in Table 3.

Assessment of acceptability of various parts of the study A brief post-visit questionnaire was sent to all participants by email or Short Message Service (SMS) to assess the acceptability of, and seek feedback on, the different components of the study.

\section{Analyses of data collected in the pilot study}

Simple descriptive analyses of selected questions, physical measurements, and biomarkers collected in the pilot study were carried out to help inform the study protocol for the main study.

\section{Results}

Overall, 517 participants were recruited over four months from January to April 2015. The response rate was 68\% (517/769) and was similar in both recruitment sites. The primary reasons given for not taking part in the study were lack of time (60\%), lack of interest (20\%), not convinced e.g. benefits of study (10\%), or no particular reasons (10\%). There was no significant difference between the respondents and non-respondents in terms of age, gender, or occupation.

Table 4 shows the breakdown of the time taken to complete the different parts of the assessment visit. On average, the visit took between 40 to $60 \mathrm{~min}$. Of the 517 participants, 495 (95\%) filled out the questionnaire (although only 80\% completed all sections), 430 (82\%) had their physical measurements taken, and 492 (94\%) provided at least one biological specimen -, 462 (89\%) blood samples (plasma and serum), 389 (75\%) urine sample, and 409 (79\%) mouthwash sample. Many participants expressed the view that the questionnaire was too long.

Samples were transported to NYUAD laboratories within $24 \mathrm{~h}$ of the collection with no major adverse temperature effects. All tests performed at NYUAD laboratory were validated on site for accuracy, precision, linearity using Clinical Laboratory Standards Institute guidelines (CLSI- EP15A2, EP6A, EP9). Reference ranges validation were also carried out on normal subjects using the transference method published by CLSI (CLSI C28-A3). Internal Quality control materials were analysed with every analytical run to control the analytical precision using two levels, while external laboratory comparisons with Cleveland Clinic Abu Dhabi (CCAD) Laboratory were used to control for bias and inaccuracy. CCAD uses External Proficiency Quality Control material from the College

Table 2 Summary of Physical Measurements of the UAE Healthy Future pilot study

\begin{tabular}{ll}
\hline Measurement category & Instrument detail \\
\hline Physical Measurements & \\
Anthropometrics & $\begin{array}{l}\text { Standing and sitting height (Seca 202, Germany), body mass and bio } \\
\text { impedance analysis (Tanita MC-780 MA body analyzer, Tanita Corporation, } \\
\text { Tokyo, Japan), neck, waist, and hip circumference (Wessex non-stretchable sprung tape). }\end{array}$ \\
Hand grip strength & Right and left-hand grip strengths (Jamar hydraulic hand dynamometer, Patterson Medical, IL, USA). \\
Peripheral blood pressure and heart rate & Blood pressure measured twice (Omron M10-IT, Omron corporation, Kyoto, Japan) \\
\hline
\end{tabular}


Table 3 List of routine and advanced biochemical markers measured

\begin{tabular}{|c|c|}
\hline Variable Category & Analyte \\
\hline \multirow[t]{4}{*}{ Bone markers } & Calcium \\
\hline & Phosphorus \\
\hline & Uric acid \\
\hline & Vitamin D \\
\hline \multirow[t]{5}{*}{ Diabetes } & Glucose \\
\hline & Glycated hemoglobin A1c \% (HBA1c \%) \% \\
\hline & $\begin{array}{l}\text { Serum receptor for advanced glycation } \\
\text { end-products (RAGE) - endogenous } \\
\text { secretory (es)RAGE and soluble (s)RAGE }\end{array}$ \\
\hline & Carboxymethil-lysine \\
\hline & $\begin{array}{l}\text { Homeostatic model assessment - insulin } \\
\text { resistance (HOMA-IR) test on fasting } \\
\text { participants }\end{array}$ \\
\hline $\begin{array}{l}\text { Electrolytes and renal } \\
\text { function tests }\end{array}$ & Chloride \\
\hline \multirow{4}{*}{$\begin{array}{l}\text { Electrolytes and renal } \\
\text { function tests }\end{array}$} & Serum creatinine \\
\hline & Potassium \\
\hline & Sodium \\
\hline & Urea nitrogen \\
\hline Full blood count & Full blood count \\
\hline Inflammation markers & C-Reactive protein \\
\hline \multirow[t]{6}{*}{ Lipid profile } & Cholesterol \\
\hline & High density lipoprotein \\
\hline & Low density lipoprotein \\
\hline & Triglycerides \\
\hline & Apolipoprotein A \\
\hline & Apolipoprotein B \\
\hline \multirow[t]{7}{*}{ Liver function tests } & Albumin \\
\hline & Alkaline phosphatase \\
\hline & Alanine transaminase \\
\hline & Aspartate transaminase \\
\hline & Gamma glutamyl transferase \\
\hline & Total bilirubin \\
\hline & Total protein \\
\hline \multirow[t]{2}{*}{ Minerals } & Iron \\
\hline & Magnesium \\
\hline \multirow[t]{6}{*}{ Urine } & Potassium \\
\hline & Sodium \\
\hline & Nitrogen \\
\hline & Micro albumin \\
\hline & Enzymatic Creatinine \\
\hline & Cotinine \\
\hline
\end{tabular}

Table 4 Time spent in the different recruitment stations

\begin{tabular}{|c|c|c|}
\hline Visit Station & Assessments & $\begin{array}{l}\text { Time taken } \\
\text { (mins) }\end{array}$ \\
\hline $\begin{array}{l}\text { Reception \& } \\
\text { consent }\end{array}$ & $\begin{array}{l}\text { - Welcome and given a printed copy } \\
\text { of the Participant Information Leaflet } \\
\text { (Arabic and English) } \\
\text { - Consent taken and form signed }\end{array}$ & $5-10$ \\
\hline Questionnaire & $\begin{array}{l}\text { - Self-administered touch-screen } \\
\text { questionnaire via tablet }\end{array}$ & $15-25$ \\
\hline $\begin{array}{l}\text { Interview \& Physical } \\
\text { Measurements }\end{array}$ & $\begin{array}{l}\text { - Interviewer questionnaire } \\
\text { - Blood pressure measurement } \\
\text { - Standing \& sitting height } \\
\text { - Body mass } \\
\text { - Waist \& hip circumference } \\
\text { - Neck circumference } \\
\text { - Bio-impedance measure } \\
\text { - Hand-grip strength }\end{array}$ & 15 \\
\hline $\begin{array}{l}\text { Specimen } \\
\text { Collection }\end{array}$ & $\begin{array}{l}\text { - Collection of blood samples } \\
\text { (about } 14 \mathrm{ml} \text { ) } \\
\text { - Urine sample }(50 \mathrm{ml}) \\
\text { - Oral wash }(10 \mathrm{ml})\end{array}$ & $5-10$ \\
\hline Total (min) & & $40-60 \mathrm{~min}$ \\
\hline
\end{tabular}

of American Pathologists (CAP) and is accredited by CAP.

Of the 517 participants, 495 were included in the final analysis due to missing data. Age distribution ranged from 18 to 70 years (67\% male) with the majority being below 40 years old among both males and females. The mean age \pm SD of males $(32.6 \pm 10.7, n=332)$ was significantly higher $(P<0.01)$ than that of females $(30.0 \pm 9.9$, $n=159)$ as shown in Fig. 1.

Table 5 shows selected baseline socio-demographic characteristics among the participants of the pilot study, by sex.

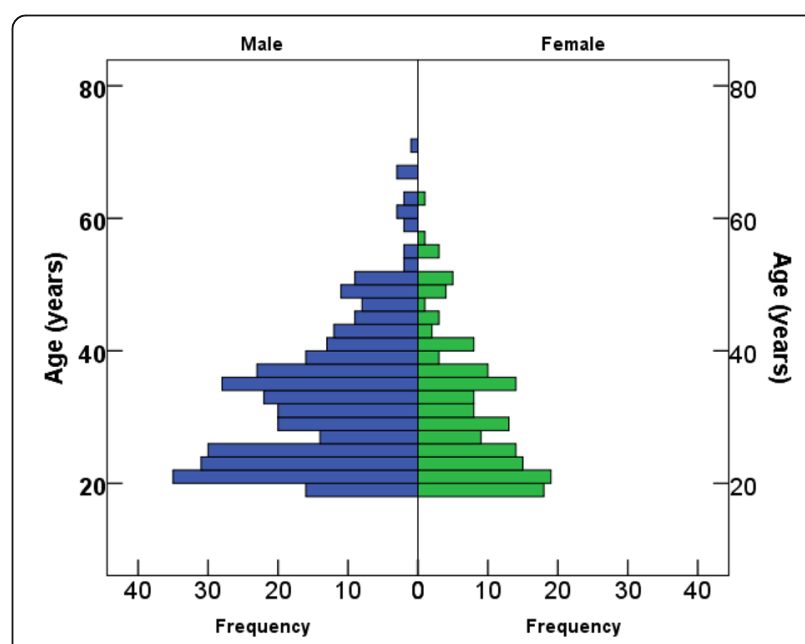

Fig. 1 Age distribution of the pilot study participants $(n=495)$ among men (32.6 $\pm 10.6, n=332)$ and women $(30.1 \pm 9.9, n=159)$ 
Table 5 Selected baseline socio-demographic characteristics among the participants of the UAE Heath Future pilot study, by sex. $(N=491)$

\begin{tabular}{|c|c|c|c|c|c|}
\hline & & \multicolumn{4}{|c|}{ Gender } \\
\hline & & \multicolumn{2}{|c|}{ Male } & \multicolumn{2}{|c|}{ Female } \\
\hline & & $\bar{N}$ & $\%$ & $\bar{N}$ & $\%$ \\
\hline \multirow[t]{5}{*}{ Age Group } & $<25$ & 98 & 29.5 & 59 & 37.1 \\
\hline & $25-34$ & 104 & 31.3 & 55 & 34.6 \\
\hline & $35-44$ & 81 & 24.4 & 29 & 18.2 \\
\hline & $45-54$ & 37 & 11.1 & 12 & 7.5 \\
\hline & $>55$ & 12 & 3.6 & 4 & 2.5 \\
\hline \multirow[t]{7}{*}{ Education } & Illiterate & 7 & 2.2 & 1 & 0.7 \\
\hline & Primary school & 41 & 13.1 & 5 & 3.3 \\
\hline & Secondary school & 133 & 42.5 & 71 & 46.4 \\
\hline & University & 105 & 33.5 & 68 & 44.4 \\
\hline & Postgraduate & 13 & 4.2 & 4 & 2.6 \\
\hline & Prefer not to answer & 10 & 3.2 & 2 & 1.3 \\
\hline & None of the above & 4 & 1.3 & 2 & 1.3 \\
\hline \multirow[t]{4}{*}{ Marital status } & Single & 107 & 34.2 & 81 & 52.9 \\
\hline & Married & 196 & 62.6 & 57 & 37.3 \\
\hline & Divorced & 10 & 3.2 & 12 & 7.8 \\
\hline & Widowed & 0 & 0.0 & 3 & 2.0 \\
\hline \multirow[t]{9}{*}{ Employment status } & Paid or self-employed & 163 & 52.1 & 62 & 40.5 \\
\hline & Retired & 12 & 3.8 & 1 & 0.7 \\
\hline & Looking after home or family & 41 & 13.1 & 23 & 15.0 \\
\hline & Unable sickness or disability & 0 & 0.0 & 0 & 0.0 \\
\hline & Unemployed & 10 & 3.2 & 17 & 11.1 \\
\hline & Unpaid or voluntary & 3 & 1.0 & 0 & 0.0 \\
\hline & Student & 22 & 7.0 & 22 & 14.4 \\
\hline & Prefer not to answer & 33 & 10.5 & 16 & 10.5 \\
\hline & None of the above & 29 & 9.3 & 12 & 7.8 \\
\hline
\end{tabular}

Table 6 Crude (not age-adjusted) prevalence of self-reported chronic diseases among the participants of the UAE Health Future pilot study, by sex

\begin{tabular}{|c|c|c|c|c|}
\hline & \multicolumn{2}{|c|}{$\begin{array}{l}\text { Male } \\
(N=267)\end{array}$} & \multicolumn{2}{|c|}{$\begin{array}{l}\text { Female } \\
(N=140)\end{array}$} \\
\hline & $\mathrm{N}$ & $\%$ & $\mathrm{~N}$ & $\%$ \\
\hline Age $($ mean $\pm S D)$ & $33(11)$ & & $30(10)$ & \\
\hline Diabetes & 20 & 8 & 5 & 4 \\
\hline Hypertension & 28 & 11 & 16 & 11 \\
\hline High Cholesterol & 49 & 18 & 18 & 13 \\
\hline \multicolumn{5}{|l|}{ Current smoking } \\
\hline Cigarette & 51 & 18 & 1 & 1 \\
\hline Midwakh (local pipe) & 52 & 18 & 1 & 1 \\
\hline Sheesha (water pipe) & 41 & 14 & 2 & 1 \\
\hline
\end{tabular}



Fig. 2 Body size categories based on body mass index cut-off points from the World Health Organization, by sex

Table 6 shows the crude (not age-adjusted) prevalence of self-reported chronic diseases among the participants stratified by sex.

Figures 2, 3, 4, 5 show the prevalence of overweight and obesity, pre-diabetes and diabetes, hypertension, and hypercholesterolemia.

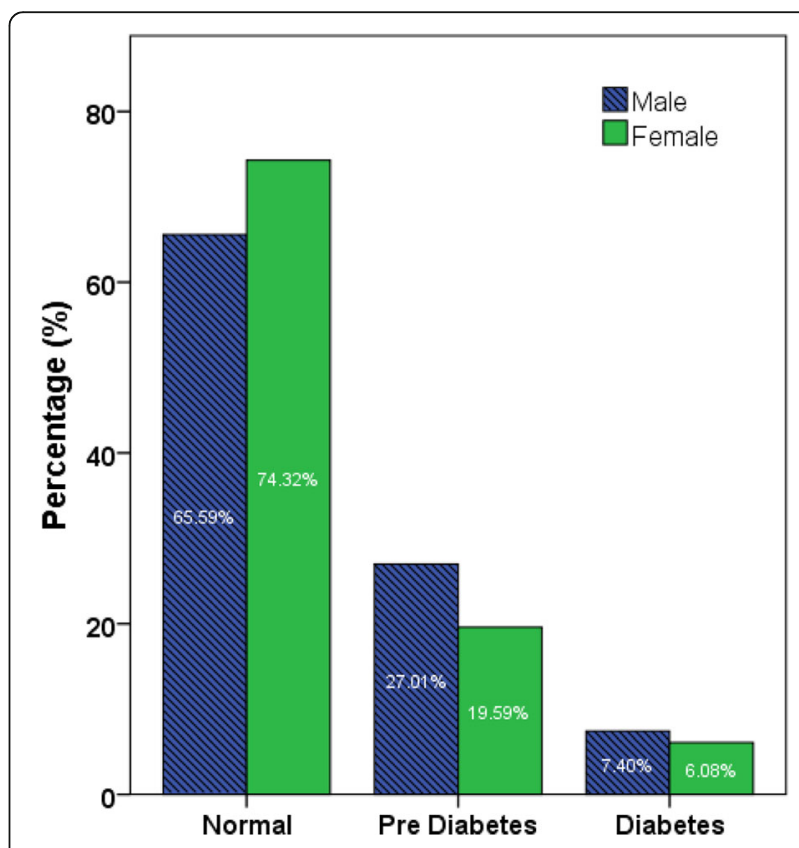

Fig. 3 Prevalence of pre-diabetes (HBA1c 5.7 to $6.4 \%$ ) and diabetes (>6.5\%) according to HbA1c levels, by sex 


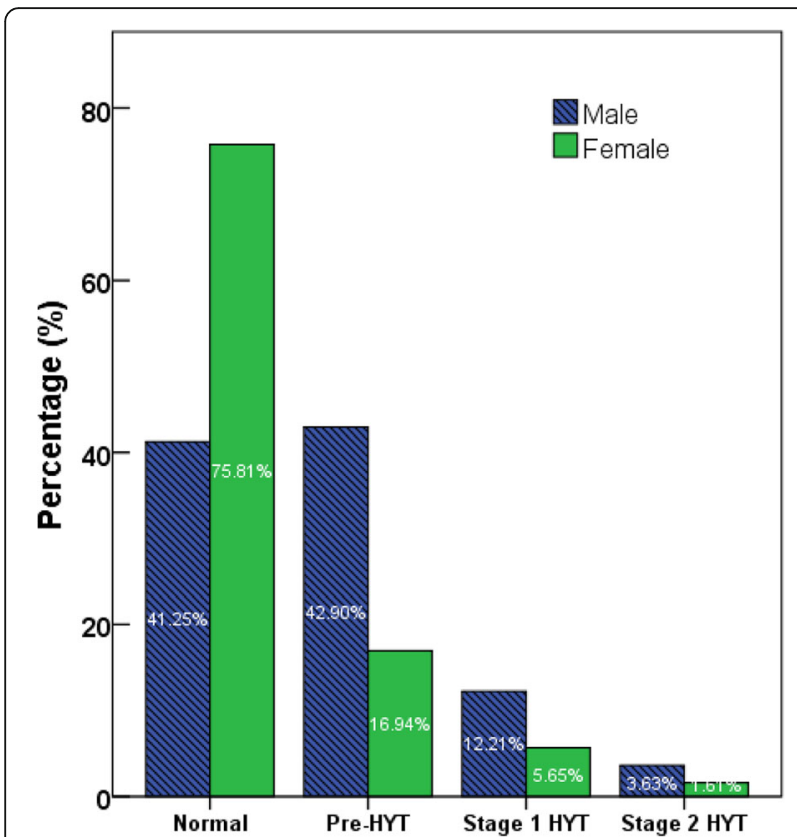

Fig. 4 Prevalence of pre-hypertension and hypertension among the participants of the UAE Heath Future pilot study, by sex

Table 7 shows the responses to the follow-up questionnaire. Of 330 questionnaires sent by email or SMS, 34 were completed $(\sim 10 \%$ response rate). Approximately $50 \%$ of the subjects reported that they fully read and understood the information leaflet. Half of the respondents thought that the length of the visit was adequate. However, 50\% thought that the

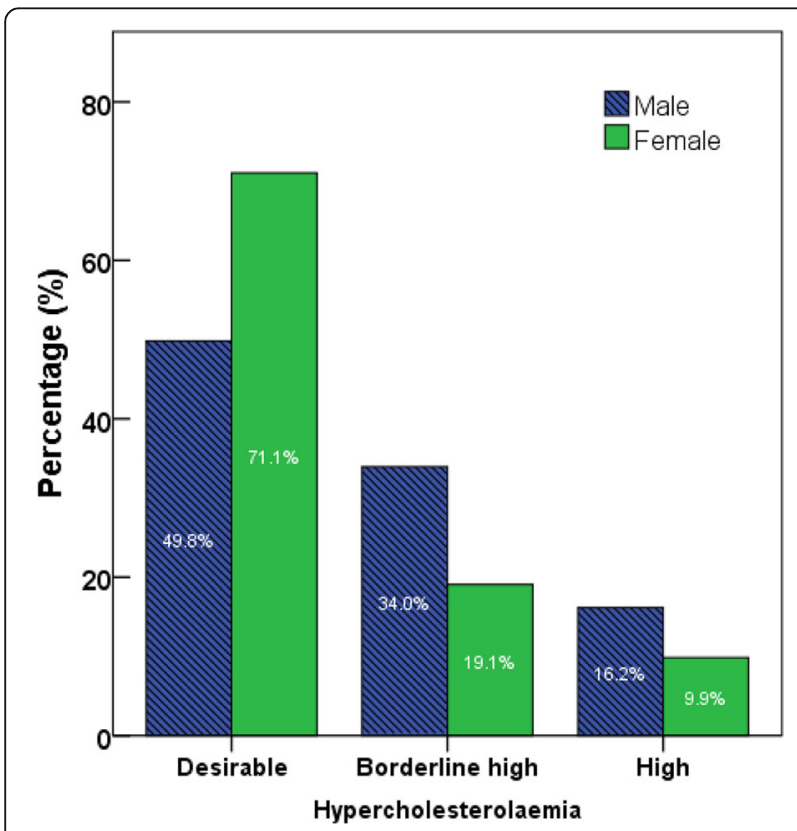

Fig. 5 Prevalence of hypercholesterolemia among the participants of the UAE Heath Future pilot study, by sex
Table 7 Responses to selected post recruitment follow-up questionnaire

\begin{tabular}{|c|c|}
\hline Question & Response \\
\hline $\begin{array}{l}\text { Did you read the Participant Information } \\
\text { Leaflet? }\end{array}$ & $\begin{array}{l}50 \% \text { in detail } \\
40 \% \text { quick look } \\
10 \% \text { no }\end{array}$ \\
\hline Was the length of the visit? & $\begin{array}{l}50 \% \text { Just right } \\
50 \% \text { too long }\end{array}$ \\
\hline $\begin{array}{l}\text { Was the amount of information you } \\
\text { were asked during the visit? }\end{array}$ & $\begin{array}{l}10 \% \text { too short } \\
40 \% \text { Just right } \\
50 \% \text { too long }\end{array}$ \\
\hline $\begin{array}{l}\text { What were your main reasons for taking } \\
\text { part in the UAEUHFS? }\end{array}$ & $\begin{array}{l}\text { To help to improve the } \\
\text { health of future generations. } \\
\text { To have a health check. } \\
\text { Support medical research. }\end{array}$ \\
\hline $\begin{array}{l}\text { How would you answer if a close friend } \\
\text { or family member were to ask you } \\
\text { "should I participate in the UAEUHFS?" }\end{array}$ & $\begin{array}{l}80 \% \text { definitely take part } \\
20 \% \text { not sure }\end{array}$ \\
\hline
\end{tabular}

questionnaire time was too long. The majority of participants indicated that helping to improve the health of future Emirati generations, having a health check, or supporting medical research as main reasons for participation. Encouragingly, the overwhelming majority $(80 \%)$ agreed that they would recommend a family member or friend to participate in the study.

\section{Discussion}

The AEHFS initiative provides for the first time a unique opportunity to identify causes and specific risk factors for NCDs among the Emirati population. The current pilot study was conducted to assess the feasibility of recruiting 20,000 UAE nationals by addressing five specific objectives including developing participants' materials, assessing participation rates for various recruitment strategies, evaluating baseline visits, assessing procedures for biological sample handling and analyses of collected data, and assessing the acceptability of the study.

Our study results show that a high proportion of UAE nationals (68\% response rate) are willing to participate in research aimed at improving the health of future generations. This high response rate establishes the feasibility of recruiting 20,000 participants for the main study. Furthermore, the highest proportion (60\%) among subjects who refused to participate did so due to time constraints only, indicative of the general acceptability of the study protocols. Considering the time taken to complete the recruitment process, a research team of one nurse and one research assistant would be able to recruit about 10 individuals per day. Thus, we think that five recruitment clinics would suffice to recruit the target number of participants within two years. Based on the experience from the pilot study, a custom-made 
laboratory information management system (LIMS) was developed to monitor sample collection, transport, storage, and biochemical analysis.

The participants of our pilot study were relatively younger than in many other longitudinal studies internationally, and even within the region [25]. This young age cohort is useful mainly because of the incidence of our primary outcome of interest, diabetes, increases rapidly from the age of 40 years. Further, a younger cohort will allow us to understand the importance of risk factors operating from early adulthood. Our current results show significantly high levels of self-reported diabetes, hypertension, and hypercholesterolemia. As expected and previously reported [26], objective measures of the prevalence of these diseases were even higher particularly among males.

The percentage of participants who responded to our follow-up questionnaire (sent by SMS or email) was relatively low at $10 \%$ and may not be reflective of the whole sample. Overall, half of the respondents understood the information leaflet, perhaps as a reflection of the high literacy rate (90\%) among participants. While patriotism was the single most important promoter to participation, the length of the questionnaire was an important obstacle, - thus, the length of the questionnaire will be reduced to improve completion rates.

\section{Conclusion}

The pilot study successfully demonstrated the feasibility of the study and recruitment for the main study that has now started and is due to be completed in 2018. As the first prospective cohort study in Abu Dhabi, the AEHFS will provide unique and substantive evidence for both lifestyle and genetic determinants of common diseases in the Emirati population. The study will be a resource for researchers throughout the UAE, and the wider region, with data accessible for all research that will be of benefit to the local population.

\section{Additional file}

Additional file 1: Participant Completed Questionnaire. (DOCX $82 \mathrm{~kb}$ )

\footnotetext{
Abbreviations

ADBB: Abu Dhabi Blood Bank; AEHFS: UAE Healthy Future study; BMI: Body mass index; HAAD: Health Authority of Abu Dhabi; IPAQ: International Physical Activity Questionnaires; LIMS: Laboratory information management system; NCD: None communicable diseases; NYUAD: New York University Abu Dhabi; PHQ-8: Personal Health Questionnaire Depression Scale; SKMC: Sheikh Khalifa Medical City; STOP-BANG: Questionnaire for Obstructive Sleep Apnea; ZMH PHCC: Zayed Military Primary Health Care Clinic; ZMH: Zayed Military Hospital (ZMH)
}

\section{Funding}

This project was funded by the New York University Abu Dhabi

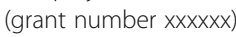

\section{Availability of data and materials}

The datasets generated and/or analysed during the current study are not publicly available pending data sharing policy but are available from the corresponding author on reasonable request.

\section{Authors' contributions}

$A A, T S, J A, T K, R R, A S, R H, S S, R A$ : Conceptualized the aim of the study and contributed to study design. AA, RR, RH, SS, RA: Contributed to data analysis, interpretation, and manuscript writing. $A A, A J, A A, A S, E Z, N O, M B, M H, F M$, $A D, S S, T L, M S, A O, L W, W M, H S, B H, F A, J Y, C l, A H, A H, M H, T A, T Z, F M, D G$, TS, OS, JA, TK, RR, AS, RH, SS, RA: Contributed to data interpretation and critically revised the article. All authors read, revised and approved the final manuscript.

\section{Ethics approval and consent to participate}

The Institutional Review Boards (IRB) of Sheikh Khalifa Medical City (SKMC), Zayed Military Hospital (ZMH), New York University Abu Dhabi (NYUAD), NYU Langone Medical Center, New York, and UAE University approved the protocols of the pilot study. All participants read and understood the information leaflet and signed the consent form prior to recruitment.

Consent for publication

Not applicable.

\section{Competing interests}

The authors declare that they have no competing interests.

\section{Publisher's Note}

Springer Nature remains neutral with regard to jurisdictional claims in published maps and institutional affiliations.

\section{Author details}

${ }^{1}$ New York University Abu Dhabi, Abu Dhabi, United Arab Emirates. ${ }^{2}$ Zayed Military Hospital, Abu Dhabi, United Arab Emirates. ${ }^{3}$ Sheikh Khalifa Medical City, Abu Dhabi, United Arab Emirates. ${ }^{4}$ UAE University, Al-Ain, United Arab Emirates. ${ }^{5}$ Cleveland Clinic Abu Dhabi, Abu Dhabi, United Arab Emirates. ${ }^{6}$ Khalifa University of Science Technology \& Research, Abu Dhabi, United Arab Emirates. 'Zayed University, Abu Dhabi, United Arab Emirates. ${ }^{8} \mathrm{Abu}$ Dhabi Police Medical Services, Abu Dhabi, United Arab Emirates. ${ }^{9}$ University of Oxford, Oxford, UK. ${ }^{10}$ New York University School of Medicine, New York, NY, USA.

Received: 19 December 2016 Accepted: 20 December 2017

Published online: 05 January 2018

\section{References}

1. International Monetary Fund. World Economic Outlook Database, October 2012: nominal GDP list of countries. Data for the years 1980-2012. Available http://www.imf.org/external/pubs/ft/weo/2012/02/weodata/index.aspx (Accessed 10 Oct 2016).

2. Ng S, Zaghloul S, Ali H, Harrison G, Yeatts K, El Sadig M, et al. Nutrition transition in the United Arab Emirates. EJCN. 2011;65:1328-37.

3. Trainer S. Body image, health, and modernity: Women's perspectives and experiences in the United Arab Emirates. APJPH. 2010:22:60S-7S.

4. Statistics Centre Abu Dhabi. Health statistics 2010. Available http://www. scad.ae. Accessed 15 October 2016.

5. Afshin A, Micha R, Khatibzadeh S, Fahimi S, Shi P, Powles J, et al. The impact of dietary habits and metabolic risk factors on cardiovascular and diabetes mortality in countries of the Middle East and North Africa in 2010: a comparative risk assessment analysis. BMJ Open. 2015;5:e006385.

6. Hajat C, Harrison O, Al SZ. Weqaya : a population-wide cardiovascular screening program in Abu Dhabi. United Arab Emirates AJPH. 2012;102:909-14.

7. Peto R, Lopez AD, Boreham J, Thun M, Heath C Jr. Mortality from tobacco in developed countries: indirect estimation from national vital statistics. Lancet. 1992;339(8804):1268-78 
8. Ezzati M, Lopez A, Rodgers A, Vander Hoorn S. MurrayCJ. Comparative Risk Assessment Collaborating Group Selected major risk factors and global and regional burden of disease The Lancet. 2002;360:1347-60.

9. Fahed A, El-Hage-Sleiman A, Farhat T, Nemer GM. Diet, genetics, and disease: a focus on the Middle East and North Africa region. J Nutr and Metab. 2012;2012:1-19.

10. Seymour G, Ford P, Cullinan M, Leishman S, Yamazaki K. Relationship between periodontal infections and systemic disease. CMI. 2007;13:3-10

11. Sommer I, Griebler U, Mahlknecht P, Thaler K, Bouskill K, Gartlehner G, et al. Socioeconomic inequalities in non-communicable diseases and their risk factors: an overview of systematic reviews. BMC Public Health. 2015;15:914.

12. Al-Houqani M, Ali R, Hajat C. Tobacco smoking using Midwakh is an emerging health problem - evidence from a large cross-sectional survey in the United Arab Emirates. PLoS One. 2012;7(6):e39189.

13. Moh'd Al-Mulla Al, Abdou Helmy S, Al Lawati J, Al Nasser S, Ali Abdel Rahman S, Almutawa A, et al. Prevalence of Tobacco Use Among Students Aged 13-15 Years in Health Ministers' Council/Gulf Cooperation Council Member States, 2001-2004. J School Health 2008;78(6):337-343.

14. Henry C, Lightowler H, Al-Hourani H. Physical activity and levels of inactivity in adolescent females ages 11-16 years in the United Arab Emirates. Am J Hum Biol. 2004;16:346-53.

15. Teo K, Chow CK, Vaz M, Rangarajan S, Yusuf S. PURE Investigators-Writing Group. The prospective urban rural epidemiology (PURE) study: examining the impact of societal influences on chronic noncommunicable diseases in low-, middle-, and high-income countries. AHJ. 2009;158:1-7.

16. Obaid Y, Al Hamiz A, Abdulle A, Hayes R, Sherman S, Ali R. Perceptions and attitudes towards medical research in the United Arab Emirates: results from the Abu Dhabi cohort study (ADCS) focus group discussions. PLoS One. 2016;11:e0149609.

17. Sudlow C, Gallacher J, Allen N, Beral V, Burton P, Danesh J, et al. UK biobank: an open access resource for identifying the causes of a wide range of complex diseases of middle and old age. PLoS Med. 2015;12:e1001779.

18. Macintyre S, McKay L, Der G. Socio-economic position and health: what you observe depends on how you measure it. JPH. 2003;25:288-94.

19. Bener A, Özkan T, Lajunen T. The driver behaviour questionnaire in Arab gulf countries: Qatar and United Arab Emirates. AAP. 2008;40:1411-7.

20. Ivers R, Blows S, Stevenson M, Norton RN, Williamson A, Eisenbruch M, et al. A cohort study of 20822 young drivers: the DRIVE study methods and population. Injury Prevention. 2006;12:385-9.

21. Alhouqani S, Al Manhali M, Al Essa A, Al-Houqani M. Evaluation of the Arabic version of STOP-Bang questionnaire as a screening tool for obstructive sleep apnea. Sleep and Breathing. 2015;19:1235-40.

22. Ben-Noun L, Sohar E, Laor A. Neck circumference as a simple screening measure for identifying overweight and obese patients. Obes Res. 2001;9:470-7.

23. Chobanian AV, Bakris GL, Black HR, Cushman WC, Green LA, Izzo JL Jr, et al. Joint National Committee on prevention, seventh report of the joint National Committee on prevention, detection, evaluation, and treatment of high blood Pressure.National Heart, Lung, and Blood Institute; National High Blood Pressure Education Program Coordinating Committee. Hypertension. 2003;42(6):1206-52.

24. Vogt HB. Hyperlipoproteinemias: part II. Screening and patient classification. S D J Med. 1991;44(3):69-71.

25. Al Kuwari H, Al Thani A, Al Marri A, Al Kaabi A, Abderrahim H, Afifi N, et al. The Qatar biobank: background and methods. BMC Public Health. 2015;15:1208.

26. Hajat C, Harrison O, Al Siksek Z. Weqaya: a population-wide cardiovascular screening program in Abu Dhabi, United Arab Emirates. Am J Public Health. 2012:102(5):909-14.

\section{Submit your next manuscript to BioMed Central and we will help you at every step:}

- We accept pre-submission inquiries

- Our selector tool helps you to find the most relevant journal

- We provide round the clock customer support

- Convenient online submission

- Thorough peer review

- Inclusion in PubMed and all major indexing services

- Maximum visibility for your research

Submit your manuscript at www.biomedcentral.com/submit 